\title{
The value of peri-operative nutrition in the sick patient
}

\author{
BY STEVEN D. HEY ${ }^{1,2}$, LESLIE G. WALKER ${ }^{3}$ AND OLEG EREMIN ${ }^{2}$ \\ ${ }^{1}$ Surgical Nutrition and Metabolism Unit, ${ }^{2}$ Department of Surgery and ${ }^{3}$ Behavioural Oncology Unit, \\ University of Aberdeen, Aberdeen AB9 $2 Z D$
}

It is now 60 years since Hiram Studley (1936) demonstrated the importance of weight loss in patients who were undergoing surgery. He studied forty-six patients with chronic peptic ulcer disease and examined the role of age of the patient, the type of surgery, the presence of pyloric stenosis, the duration of surgery and the surgeon, as possible prognostic indicators. None of these factors was shown to be important in predicting the patients outcome following surgery. However, it was observed that the amount of weight lost preoperatively did predict post-operative outcome. Although seven of the forty-six patients died in the post-operative period, six of these patients had lost more than $20 \%$ of their body weight. In contrast, only one patient who had lost less than $20 \%$ of their body weight died.

More recent studies have shown that malnutrition is still a problem in $40 \%$ of hospitalized patients. Furthermore, in patients who are undergoing gastrointestinal surgery, up to $30 \%$ can be classified as having 'moderate' malnutrition (Detsky et al. 1987). This weight loss is associated with alterations in protein and fat metabolism, cellular function, modulation of intracellular enzyme activities, and defects in function of the immune system, skeletal muscle and respiratory function, and wound healing (Hill, 1992). It is not surprising, therefore, that weight loss is associated with an increased post-operative mortality and morbidity in patients undergoing surgery (Meguid et al. 1990). Nutritional support has been given to patients undergoing surgery, therefore, with the aim of reversing weight loss, improving nutritional status and reducing the risks of post-operative morbidity and mortality.

The present paper will review the role of nutritional support given to patients in the peri-operative period by the parenteral and enteral routes. In addition, the role of specific nutrients and their use in such patients will also be examined.

\section{PARENTERAL NUTRITION IN THE PERI-OPERATIVE PERIOD}

The role of total parenteral nutrition (TPN) in the peri-operative period in preventing postoperative complications and in reducing post-operative mortality has been investigated in prospective randomized controlled studies (Table 1). These studies have frequently involved small numbers of patients, have employed different nutritional regimens (both in duration of pre- and post-operative feeding and different energy and protein intakes), and have often evaluated different study end-points, e.g. effects on biochemical indices of nutritional status (e.g. serum protein levels, $\mathrm{N}$ balance studies), anthropometric markers of nutritional status (e.g. body composition, skinfold thickness), or on clinical variables (e.g. complications, infective episodes and mortality).

The first randomized trial designed to evaluate the role of peri-operative parenteral nutritional support was reported by Holter \& Fischer (1977). They evaluated fifty-six patients with cancers of the gastrointestinal tract who had lost weight and were to undergo surgical resection of the tumours. The patients received either TPN ( $80 \mathrm{~g}$ protein with 8.3 $\mathrm{MJ} / \mathrm{d}$ ) for $3 \mathrm{~d}$ before surgery and for $10 \mathrm{~d}$ post-surgery or not to receive any nutritional support. The findings from this study demonstrated that the group of patients receiving 
S. D. HEYS $E T A L$

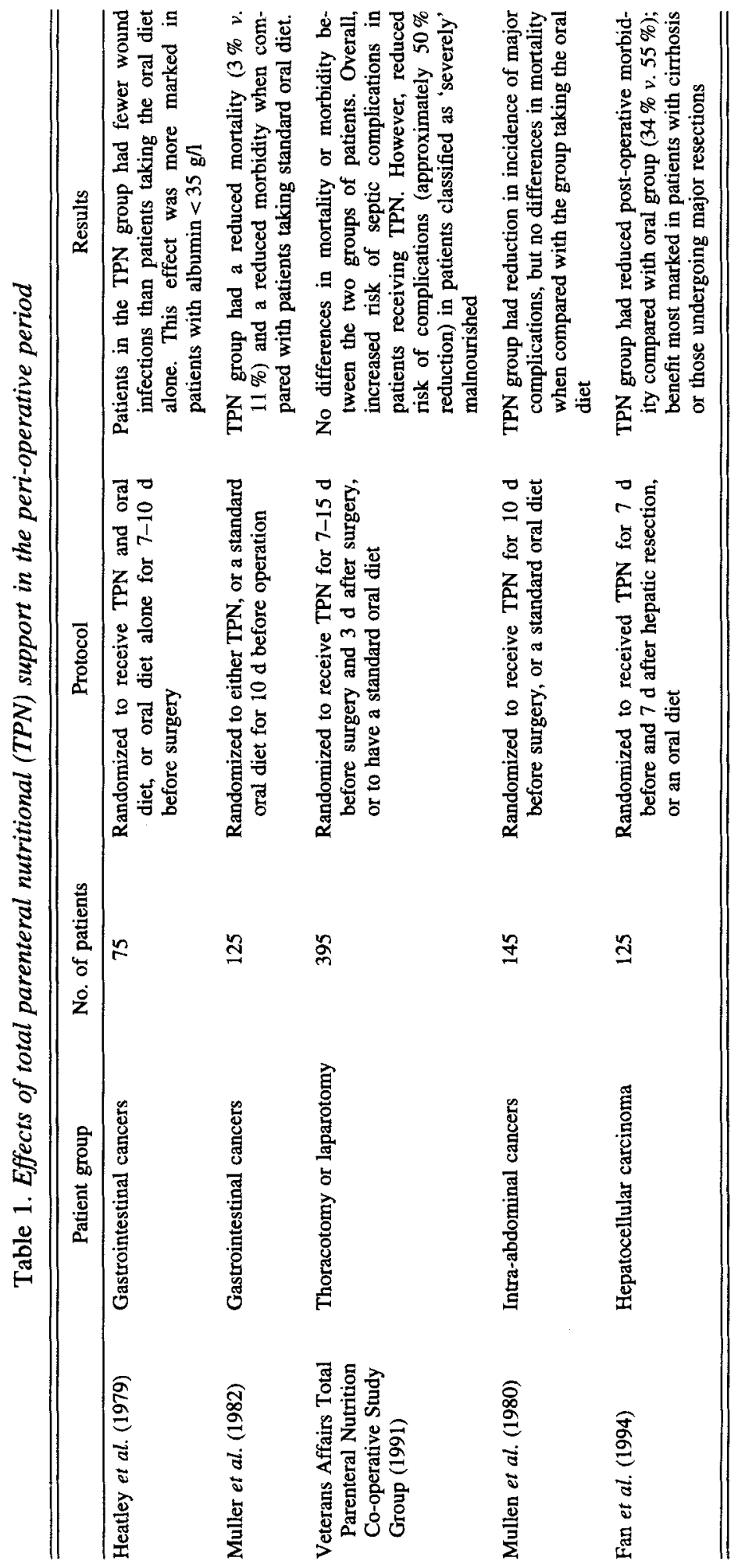


TPN had a reduction in the incidence of major complications of approximately $30 \%$, although this did not achieve statistical significance. A clinical benefit of TPN in the perioperative period was first reported by Moghissi et al. (1977). Patients with carcinoma of the oesophagus were randomized to receive either TPN given for 5-7 d before surgery and then for 6-7 d post-operatively, or to receive intravenous crystalloids and no nutritional support. The benefits noted in the TPN group of patients were an improved $\mathrm{N}$ balance (positive in the TPN patients but negative in the group receiving intravenous fluids) and better wound healing.

A larger study was subsequently reported by Heatley et al. (1979) which also suggested a beneficial effect of TPN given to patients in the peri-operative period. A total of seventy-five patients with upper gastrointestinal cancers received either a standard hospital diet (12.5 MJ and $15 \mathrm{~g} \mathrm{~N} / \mathrm{d}$ ) or the standard hospital diet supplemented with TPN $(167 \mathrm{~kJ} / \mathrm{d})$. These nutritional regimens were given for $10 \mathrm{~d}$ pre-operatively. The patients receiving the TPN supplementation were observed to have fewer wound infections than those receiving the standard oral diet only. Furthermore, this reduction in wound infections only occurred in patients who had a serum albumin concentration of less than $35 \mathrm{~g} / \mathrm{l}$ before entering the study.

A beneficial effect of the provision of TPN in the peri-operative period was demonstrated by Muller et al. (1982). This was a relatively large study of 125 patients who had intra-abdominal cancers of various types. Patients were randomized to receive either TPN ( $1.5 \mathrm{~g}$ amino acids/ $\mathrm{kg}$ per $\mathrm{d}$ and $11 \mathrm{~g}$ glucose $/ \mathrm{kg}$ per $\mathrm{d}$ ), given for $10 \mathrm{~d}$ before surgery, or a standard hospital diet $(10.0 \mathrm{MJ} / \mathrm{d})$. Two main beneficial effects of TPN were observed; there was a significant reduction in the risks of post-operative complications (anastomotic leak, peritonitis, intra-abdominal abscesses, ileus) and also the post-operative mortality was reduced by threefold in patients receiving TPN. Clinical benefit with supplemental nutrition has not been a consistent finding and other studies have failed to show significant benefit from nutritional support. However, other beneficial effects such as improvements in serum proteins, $\mathrm{N}$ balance, nutritional status, reduction in the duration of hospital stay have been reported.

A larger study evaluating the effect of TPN in the peri-operative period was reported recently by the Veterans Affairs Total Parenteral Nutrition Co-operative Study Group (1991). This study was a multi-institutional, prospective, randomized controlled trial which had been designed in an attempt to provide a definitive answer to the question of the benefits of nutritional support in the peri-operative period. The patients included in this study were undergoing elective laparotomy or thoracotomy, with approximately two-thirds of patients having malignant disease. A total of 3259 patients were considered for the study, but after a variety of exclusions (e.g. not expected to survive for $90 \mathrm{~d}$, had TPN within the last $15 \mathrm{~d}$ or undergone other surgical procedures within the previous month), 395 patients were studied. These patients were all classified as being 'malnourished' (according to a nutrition risk index, $(1.519 \times$ serum albumin $(\mathrm{g} / \mathrm{l})+0.417 \times($ current weight/usual weight) $\times 100$; a value of less than 83.5 defined those who were severely malnourished), or a combination of weight loss, a reduced serum albumin and/or reduced serum prealbumin). Patients were randomized to receive either TPN (4.2 MJ above resting energy expenditure and energy: $\mathrm{N} 150: 1$ ) or a control diet (standard hospital diet pre-operatively, fluids for the first $72 \mathrm{~h}$ post-surgery and oral feeding thereafter as clinically indicated). The patients were followed up for $90 \mathrm{~d}$ following surgery.

The primary end-points of this study were the incidence of major post-operative complications, with secondary end-points being mortality, all complications, infectious complications, non-infectious complications, and major complications after stratification 
for the patient's underlying degree of malnutrition. The results of this study revealed that the incidence of major complications was similar for the TPN and control groups of patients. There was, however, a higher rate of infectious complications in the TPN group, when compared with the control group $(14 \% v .6 \%)$. In addition, there was a small increase in the incidence of non-infectious complications in the control group $(17 \% \mathrm{v}$. $22 \%$ ), but this did not achieve statistical significance. However, it was noted that this increase was mainly in those patients who were categorized as either 'borderline' or 'mildly' malnourished. A subgroup analysis of complications encountered by the patients according to their nutritional state demonstrated an important finding. The 'severely'malnourished group of patients (comprising a total of only fifty patients) experienced fewer non-infectious complications than did the control patients $(5 \% v .43 \%)$, but there was no difference in infectious complications. However, it should be noted that only fifty patients fell into the severely malnourished category. This study again confirmed that TPN was of limited benefit in minimally-malnourished patients, although the severely-malnourished patients (less than $5 \%$ of the study population) may benefit from pre-operative TPN.

Fan et al. (1994) have also reported beneficial effects of peri-operative TPN in certain patients with primary liver cancer who were undergoing surgical resection. In this study, patients were randomized to receive either peri-operative TPN for $7 \mathrm{~d}$ before and $7 \mathrm{~d}$ after, surgery or alternatively to receive oral intake before surgery and intravenous fluids and electrolytes following surgery. Patients in the TPN group had less post-operative morbidity $(34 \%$ v. $55 \%)$ and fewer infectious complications $(17 \% v .37 \%)$, than patients in the control group. The patients who benefited most from TPN were those with cirrhosis. In this subgroup of patients with cirrhosis, TPN supplementation resulted in a lowering of the post-operative morbidity by almost $50 \%$. Furthermore, patients undergoing a 'major' hepatectomy also benefited, with a significant reduction in post-operative morbidity.

\section{ENTERAL NUTRITION}

The enteral route of nutrient administration has also been used in the provision of nutrition to patients in the peri-operative period. Although there are many advantages associated with the provision of nutrients by the enteral route, recent interest has focused on the barrier function of the gut. Under normal circumstances the gut prevents the entry of bacteria and endotoxin into the systemic circulation, hence preventing their widespread dissemination. The maintenance of this normal gut barrier function requires the interaction of several factors, e.g. the resident intestinal microflora, normal gut motility, normal intestinal epithelial structure and function, hormones and the provision of intraluminal nutrients.

Experimental studies in animals receiving TPN for short periods have shown that this can result in mucosal atrophy (Mainous et al. 1991) and bacterial translocation (Li et al. 1989). Moreover, these changes can be reversed by the provision of enteral nutrition. Studies in patients receiving TPN have also demonstrated changes in the gut wall. For example, TPN has resulted in significant decreases in mucosal thickness and reduced heights of both the villi and microvilli (Guedon et al. 1986; van der Hulst et al. 1993), decreased intestinal mucosal brush-border enzyme activity (Guedon et al. 1986), and an increased intestinal permeability to lactulose (van der Hulst et al. 1993). The importance of this impairment in intestinal barrier function is that there is an increased incidence of infective complications in patients (Sedman et al. 1994). 


\section{Studies evaluating enteral nutrition in the peri-operative period}

Studies have also evaluated the role of enteral nutrition, given in the peri-operative period, to patients undergoing surgery. A variety of feeding regimens have been employed and the majority of these studies have provided the nutritional support following surgery. However, there have been two reports of the use of enteral nutritional support given before surgical intervention (Shukla et al. 1984; Meijerink et al. 1992; Table 2).

In the first of these studies (Shukla et al. 1984), 110 malnourished patients were randomized to receive enteral hyperalimentation $(14.6-16.7 \mathrm{MJ} / \mathrm{d})$ for $10 \mathrm{~d}$ or a standard diet. It was found that patients receiving enteral hyperalimentation had an improved nutritional status (serum albumin and anthropometric indices), enhanced immune function (cellular and humoral immunity) and a better $\mathrm{N}$ balance than patients eating a standard diet. In addition, there were also clinical benefits in the supplemented group of patients that were observed in the post-operative period. These latter patients had a reduced risk of wound infection ( $11 \% v .37 \%)$, a reduced hospital stay $(10 \mathrm{~d} v .13 \mathrm{~d})$ and a lower mortality ( $6 \%$ v. $12 \%)$, when compared with the non-supplemented group of patients. In the second of these studies, Meijerink et al. (1992) evaluated 151 patients with gastric or colorectal cancer in the pre-operative period. The aim of their study was to determine what effect nutritional supplementation, given through the enteral route (for $10 \mathrm{~d}$ ), had on postoperative morbidity and mortality. Patients were stratified according to weight loss (less than or greater than $15 \%$ ), age less than, or greater than 65 years, and gastric or colo-rectal tumours. They received either enteral nutritional support $(150 \%$ of basal energy expenditure), or no supplementation. The patients not receiving supplementation were split into two groups: those who were not nutritionally depleted and those who were nutritionally depleted. The results from this study revealed that there were no differences in the incidences of septic complications between the patients in the nutritional-support group and the non-nutritionally-depleted control patients. However, in patients who had lost more than $10 \%$ of their body weight, and who had over $500 \mathrm{ml}$ blood loss during surgery, there was a significant decrease in major complications as a result of nutritional support.

The role of post-operative nutritional support in patients undergoing surgery for fractured necks of femur also has been investigated, with beneficial effects being reported. Bastow et al. (1983) evaluated 744 elderly women with fractured necks of femur and divided them into three groups on the basis of anthropometric measurements (arm thickness and triceps skinfold thickness). Patients were categorized as being either 'well-nourished', 'thin' or 'very thin'. They studied 122 of these patients from the 'thin' and 'very thin' groups, in the post-operative period. The patients were randomized to a supplementary feeding regimen ( $4.2 \mathrm{MJ}$ and $28 \mathrm{~g}$ protein) given overnight, or to receive no nutritional supplementation. This feeding regimen was continued until the patients were discharged from hospital, or until they could not tolerate the nasogastric feeding tube. The supplemental feeding was well tolerated by about $80 \%$ of the patients in this group. It was documented that the supplemented group of patients had improvements in their nutritional status, as assessed by anthropometry and plasma proteins. In addition, these patients also had a shorter rehabilitation time and a reduced hospital stay when compared with patients not receiving nutritional supplementation. It was also observed that these effects were most marked in patients who were categorized as being 'very thin', The mortality in these patients was also less than that in the non-supplemented patients ( $8 \%$ v. $22 \%)$, but this did not achieve statistical significance.

Delmi et al. (1990) subsequently reported their study of nutritional support in fifty-nine elderly patients with femoral neck fractures. In this study, the patients received either a nutritional supplement $(20 \mathrm{~g}$ protein and $1.1 \mathrm{MJ} / \mathrm{d})$ or no nutritional supplementation. The supplementation began as soon as the patient entered the orthopaedic unit and was 


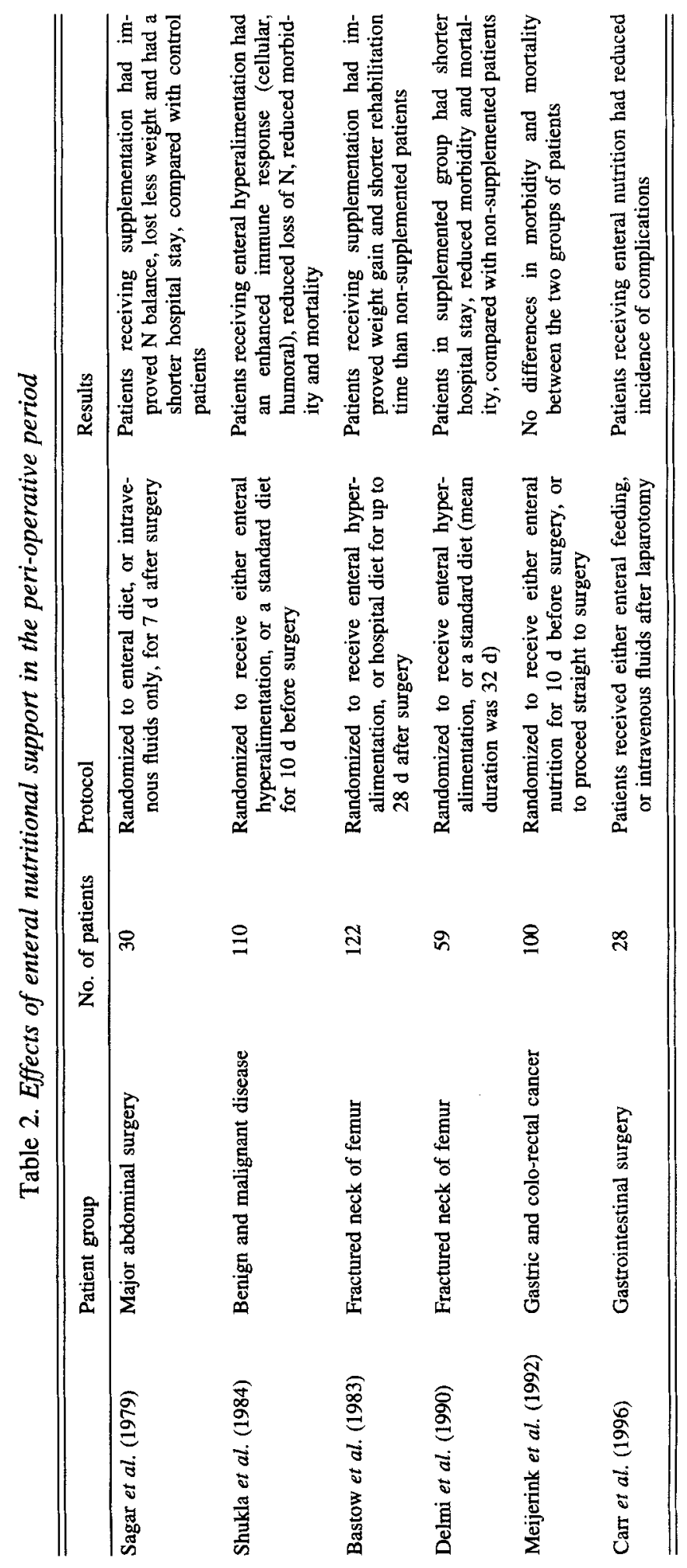


continued into the rehabilitation period. It was found that the rates of complications and deaths were significantly lower in the patients receiving nutritional supplementation. Furthermore, the supplemented patients had a reduction in complications and a lower mortality when assessed 6 months after the fracture. These authors also reported that nutritional supplementation resulted in a shorter hospital stay.

A recent study has also reported the beneficial effects of post-operative enteral nutrition in patients who have undergone major abdominal surgery (Carr et al. 1996). Thirty patients undergoing laparotomy for gastrointestinal resections were randomized to receive either immediate post-operative enteral feeding (approximately 6.9 MJ and $60 \mathrm{~g}$ protein) through a nasojejunal tube, or to have standard intravenous crystalloids, until the resumption of normal oral feeding. In this study, enteral nutrition resulted in an improved $\mathrm{N}$ balance and a significant decrease in gut permeability when compared with patients receiving intravenous fluids only. In addition, there was a significant reduction in postoperative complications in the group of patients receiving enteral nutrition.

Not all studies have demonstrated clinical benefits of enteral nutritional support (Hoover et al. 1980; Smith et al. 1985; Frankel \& Horowitz, 1989; Schroeder et al. 1991). However, other beneficial effects in terms of weight gain, $\mathrm{N}$ balance and recovery time have been reported (Sagar et al. 1979; Ryan et al 1981; Bastow et al. 1983; Shukla et al. 1984; Smith et al. 1985).

\section{Enteral or parenteral route of nutrient administration?}

Few trials have compared the efficacy of enteral $v$. parenteral nutrition in surgical patients in the peri-operative period. Moore et al. (1992) published a meta-analysis of eight randomized trials (two published and six unpublished) which had addressed this question in patients who had undergone a variety of surgical procedures. A total of 240 patients were analysed, 118 receiving enteral nutrition, and 112 receiving parenteral nutrition. This analysis revealed that there was a significant reduction in the number in the enteral nutrition group who experienced infective complications, when compared with patients receiving TPN $(18 \%$ v. $35 \%)$. Further subgroup analyses were undertaken which demonstrated that it was the patients who had experienced trauma, in particular blunt trauma, who had the most significant reduction in infective complications when given enteral nutrition rather than TPN. However, these studies have been criticized because of methodological problems in the non-published trials.

In patients with acute pancreatitis, enteral nutrition also appears to have benefits over TPN. In a small randomized trial in twenty-three patients, Windsor $e t$ al. (1996) found that enteral nutritional support resulted in a decrease in the acute-phase response and reduced the incidence of the systemic inflammatory response syndrome, when compared with patients receiving TPN. However, not all studies have demonstrated benefits of enteral nutritional support. von Meyenfeldt et al. (1992) were unable to show any difference in septic complications, morbidity and mortality, in 101 patients who were randomized to receive either enteral nutrition or TPN for $10 \mathrm{~d}$ before surgery.

\section{TARGETED NUTRITION}

\section{L-Arginine}

$\mathrm{L}$-Arginine is considered to be a non-essential amino acid which becomes essential under stressful circumstances, e.g. sepsis and trauma (Kirk \& Barbul, 1990). L-Arginine is required as a substrate for the synthesis of proteins, creatine, polyamines and NO (for 
review, see Brittenden et al. 1994a; Heys et al. 1996). However, when administered orally in large quantities (in animal experimental studies) it has important effects on immune function, $\mathrm{N}$ metabolism and wound healing (Brittenden et al. 1994a).

In studies in man it has been shown that dietary supplementation with L-arginine $(25 \mathrm{~g} /$ d) for $14 \mathrm{~d}$ resulted in an enhanced wound healing, as assessed by an increased synthesis of hydroxyproline (Barbul et al. 1977). Also, beneficial effects on $\mathrm{N}$ metabolism have been reported. Patients undergoing surgery for both benign and malignant disease have a reduced loss of $\mathrm{N}$ in the post-operative period if they receive dietary supplementation with L-arginine (Elsair et al. 1978; Daly et al. 1988).

The beneficial effects of L-arginine on the immune system have been shown in healthy volunteers and in patients with either benign or malignant diseases. Park et al. (1991) investigated the effects of adding L-arginine to the culture medium containing the lymphocytes taken from healthy volunteers. They found that this resulted in an enhanced response to mitogenic stimulation. Other studies in both healthy volunteers and patients with malignant disease have demonstrated that supplementing the diet with L-arginine results in enhanced responses to mitogens, increased natural killer (NK) and lymphokine-activated killer cell activities, and increased numbers of circulating $\mathrm{T}$ helper cells (Table 3 ).

\section{L-Glutamine}

Glutamine is the most abundant amino acid in the body, making up more than half the free intracellular amino acid pool (Bergstrom et al. 1974). It is a non-essential amino acid and its roles include: the transport of $\mathrm{N}$ between tissues, a precursor for the manufacture of purines and pyrimidines, and a fuel for a variety of cells in the body, in particular colonocytes and enterocytes. In certain circumstances, e.g. stress, sepsis and trauma, the plasma and intracellular concentrations of glutamine decrease and these decreases have been shown to correlate with patient survival (Roth et al. 1982).

Glutamine supplementation has beneficial effects on $\mathbf{N}$ metabolism in patients undergoing surgery. For example, in patients undergoing cholecystectomy, glutamine supplementation given in the post-operative period resulted in a substantial reduction in whole-body $\mathrm{N}$ loss, when compared with patients not receiving glutamine supplementation. Furthermore, the decrease in the intracellular glutamine concentration that occurred postoperatively was smaller (Hammarqvist et al. 1989). Similarly glutamine supplementation given to patients undergoing surgery for intra-abdominal malignant disease also reduced daily negative $\mathrm{N}$ balance and increased the levels of L-glutamine in skeletal muscle, when compared with non-supplemented patients.

Beneficial effects of glutamine on the immune system have been shown by O'Riordain et al. (1994). These authors studied patients with colo-rectal cancer undergoing surgical removal of the tumour. Patients received TPN, but with or without glutamine supplementation, for $6 \mathrm{~d}$ post-operatively. This study revealed that glutamine supplementation produced an increase in $\mathrm{T}$ cell lymphocyte DNA synthesis in response to mitogenic stimulation. However, there were no differences in interleukin (IL)-2, IL-6 or tumour necrosis factor (TNF) production by isolated peripheral blood mononuclear cells.

The clinical benefit of glutamine supplementation was confirmed in patients undergoing bone-marrow transplantation (Ziegler et al. 1992). After the patients had undergone transplantation, they were randomized to receive either glutamine supplementation (approximately seven times the normal daily intake) or no glutamine supplementation for 4 weeks. The results of this study revealed that not only did glutamine-supplemented patients have better improved $\mathrm{N}$ balances, but they also had fewer infections and shorter 


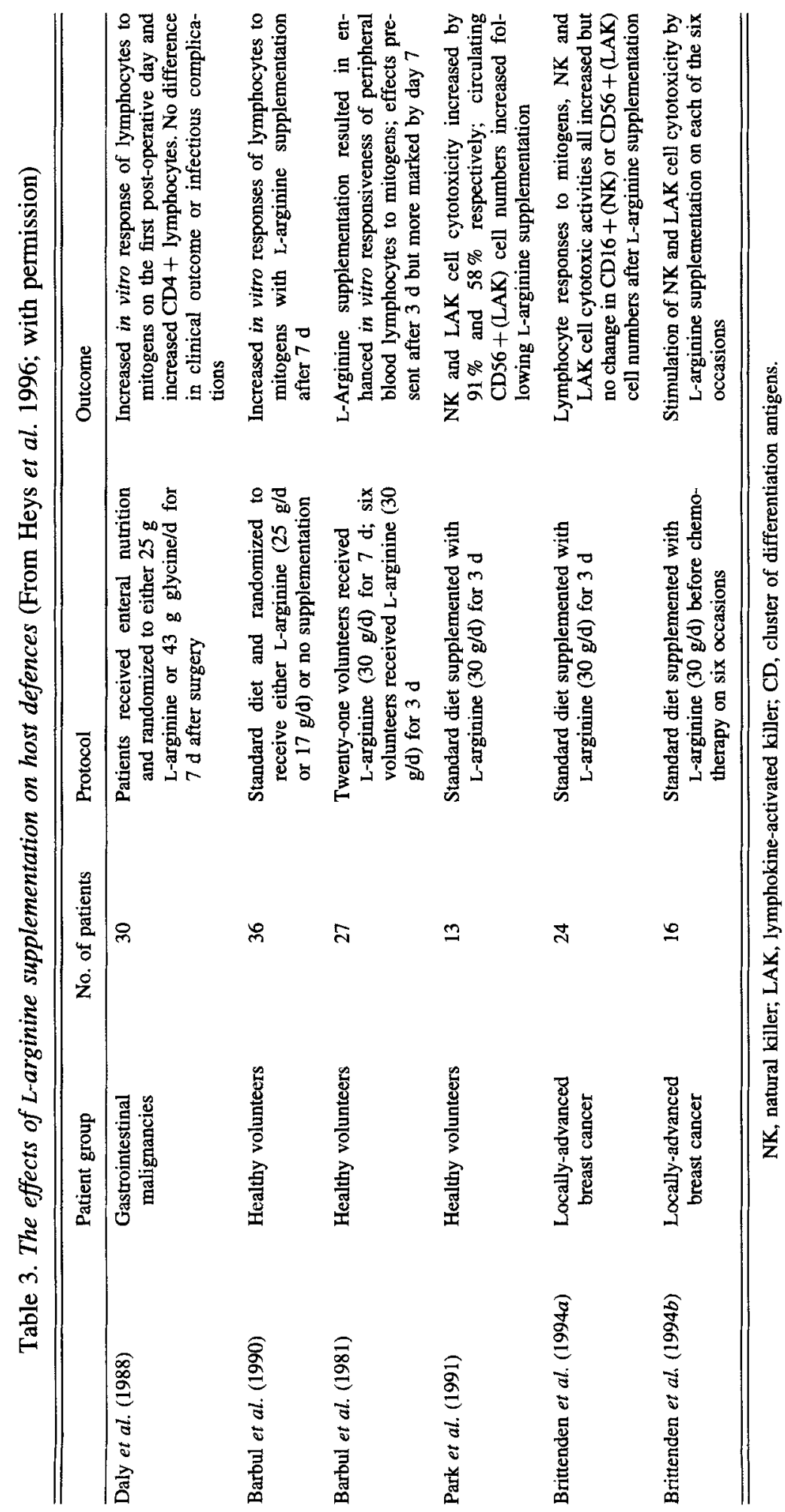


hospital stays, when compared with non-supplemented patients. However, this was a small study and further larger studies are required to confirm these clinical benefits.

\section{Essential fatty acids (EFA)}

EFA ( $n-3$ and $n-6)$ play important roles in cellular metabolism. They are important components of cell membranes and are precursors for the synthesis of a variety of substances which can regulate various aspects of metabolism and immune function, e.g. leukotrienes, prostaglandins (PG) and platelet-aggregating factors (Kinsella \& Lokesh, 1990). In particular, the potent immunosuppressor, $\mathrm{PGE}_{2}$ is derived from the metabolism of $n-6$ EFA. In contrast, the metabolism of $n-3$ EFA leads to the production of $\mathrm{PGE}_{3}$, which is a less-potent suppressor of the immune system than is $\mathrm{PGE}_{2}$ (Alexander et al. 1986). Furthermore, there is an increased production of $\mathrm{PGE}_{2}$ following traumatic injury.

This finding has prompted studies evaluating the use of $n-3$ EFA as possible enhancers of the depressed immune response that occurs in sepsis. However, the studies in animal models have revealed conflicting results; beneficial effects on survival have been reported (Mascioli et al. 1989; Barton et al. 1991), while other reports indicate that $n-3$ EFA supplementation results in either no difference in survival or worse survival (Alexander $e t$ al. 1986; Clouva-Molyvdas et al. 1992).

Studies in man, however, have indicated that dietary supplementation with $n-3$ EFA results in suppression in various aspects of the immune system in healthy volunteers (Meydani et al. 1991). Studies in patients with colo-rectal cancer have demonstrated also that supplementation with a mixture of $n-3$ and $n-6$ EFA will result in a suppression of the response of peripheral blood lymphocytes to mitogens, reduction in natural cytotoxicity and decreased levels of a range of circulating cytokines (Purasiri et al. 1994a,b, 1995). Similarly, in patients with inflammatory bowel disease, dietary supplementation with $n-3$ EFA (eicosapentaenoic acid and docosahexaenoic acid) resulted in suppression of NK cell activity (Almallah et al. 1996).

\section{Nucleotides}

Nucleotides are necessary for the synthesis of RNA and DNA, proteins, carbohydrates and lipids. Initial studies in animal experimental models demonstrated that the loss of antibodyproducing function in irradiated animals could be restored by giving the animals nucleic acid-rich material. Subsequently, synthetic polyribonucleotides were developed and shown to have a range of immunomodulatory effects in animal studies (Khan et al. 1995a). For example, polyribonucleotides resulted in a stimulation of the number and function of circulating $\mathrm{T}$ lymphocytes, increased activity of $\mathrm{T}$ suppressor cells and stimulated natural cytotoxicity (Donner et al. 1977; Morris \& Johnson, 1978; Youn et al. 1987). Furthermore, in an animal model of sepsis, polyribonucleotide administration resulted in improved survival in mice (Adeji et al. 1993). In human studies, the intravenous administration of a synthetic polyribonucleotide, polyadelylic polyuridylic acid (PAPU) stimulated macrophage function and induced the release of IL-1 $\beta, \mathrm{IL}-2, \mathrm{IL}-6, \mathrm{TNF} \alpha$ and interferon- $\gamma$ (Khan et al. 1995b; Dy et al. 1991).

\section{Clinical studies evaluating combinations of specific nutrients}

Initial trials of combinations of L-arginine, $n-3$ fatty acids and polyribonucleotides have been reported in a variety of patients, including patients undergoing surgery. The effects of 


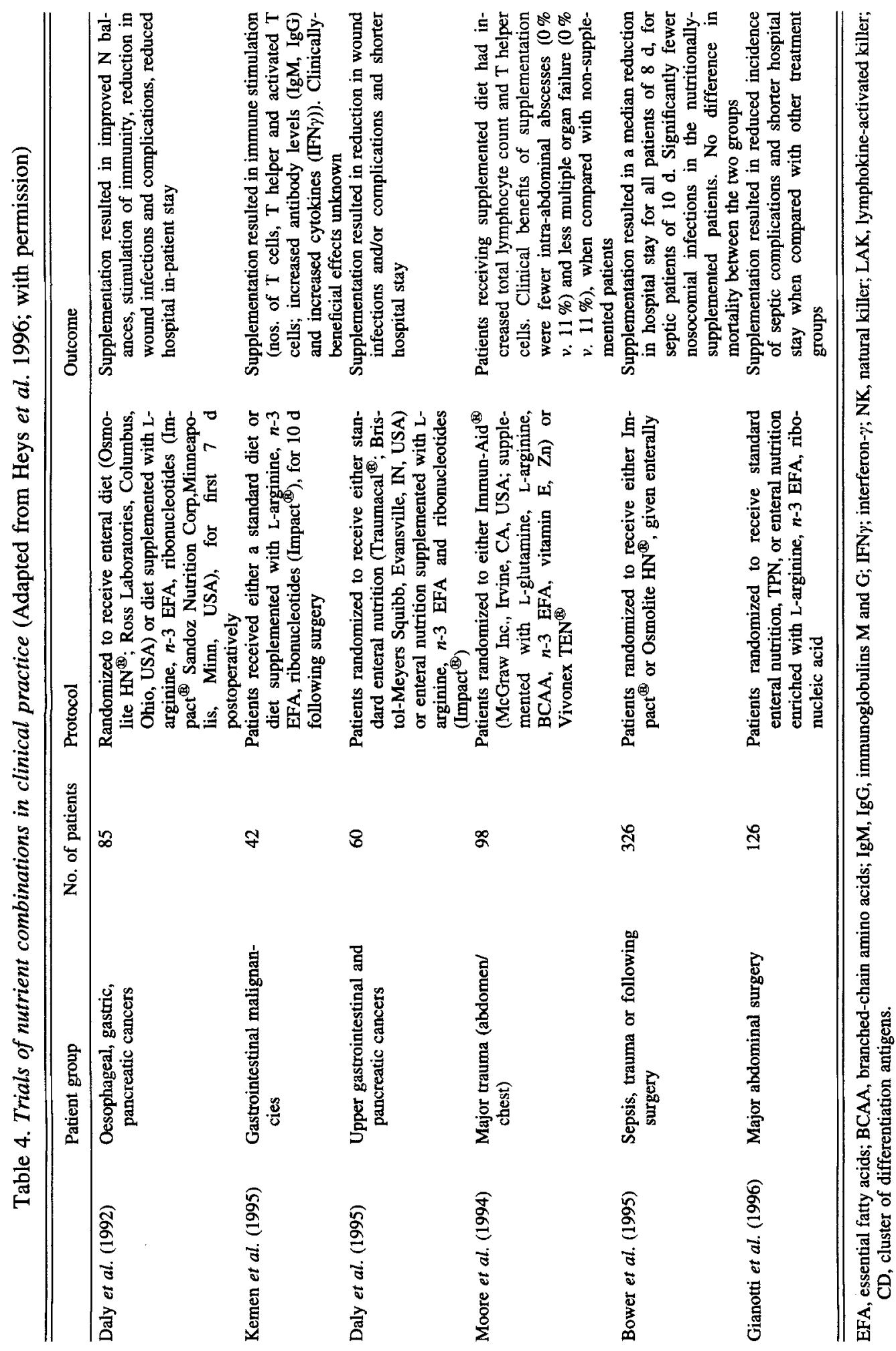


this combination of nutrients on immune function, in intensive care unit patients, were first reported by Cerra et al. (1990). This was a small study of twenty patients with either trauma or sepsis or who had undergone elective general surgery. Patients were randomized to receive either a supplemented diet (Impact ${ }^{\circledR}$; Sandoz Nutrition Corp., Minneapolis, MN, USA) or a standard diet, for up to $10 \mathrm{~d}$. It was found that the patients receiving the supplemented diet had enhanced aspects of their immune response when compared with non-supplemented patients.

A larger, multi-centre trial has also investigated the effects of supplementation with Larginine, RNA and $n$-3 EFA (Impact ${ }^{\circledR}$ ) in patients who had either undergone surgery, or experienced trauma or had major sepsis, and who required admission to an intensive care unit (Bower et al. 1995). Patients (n 326) were stratified according to their age and disease (septic or systemic inflammatory response syndrome) and then randomized to receive either a standard diet (Osmolite $\mathrm{HN}^{\circledR}$; Ross Laboratories, Columbus, $\mathrm{OH}, \mathrm{USA}$ ) or a diet supplemented with L-arginine, $n$-3 EFA and RNA (Impact ${ }^{\circledR}$ ), which was given via the enteral route. The results from this study demonstrated that the patients receiving the supplemented diet had a median reduction in hospital stay of $8 \mathrm{~d}(P<0.05)$, but for septic patients the median reduction in hospital stay was $10 \mathrm{~d}(P<0.05)$. Furthermore, there was a significant reduction in the development of nosocomial infections in the nutritionallysupplemented patients $(P<0.01)$. There was no difference, on the other hand, in mortality rates between the two groups of patients. Other studies have evaluated also the effect of combinations of nutrients on immune function and clinical outcome in a variety of patients, including those in the peri-operative period. These studies have yielded promising results and have been summarized in Table 4. However, some of these studies have been criticised because of differences in $\mathrm{N}$ intake and/or provision of trace elements and vitamins between the two groups (nutrients which may also modulate the immune response). However, further well-designed studies evaluating combinations of nutrients are required before their widespread use in clinical practice in patients in the peri-operative period.

\section{SUMMARY}

In summary, therefore, the provision of TPN to malnourished patients in the pre-operative period reduces the incidence of post-operative complications, but does not affect postoperative mortality. It is likely that the provision of nutrition by the enteral route is as effective as that by the parenteral route, and may have the extra benefit of resulting in a reduction in infectious complications when compared with patients receiving TPN. Furthermore, the use of enteral nutritional support in the post-operative period may also reduce both septic and major complications, but does not alter mortality.

The use of specific combinations of nutrients appears to offer the greatest promise in the use of peri-operative nutritional support. The initial studies reported to date demonstrate reductions in post-operative morbidity, but again there are no benefits on mortality. However, further studies to determine the optimal combinations of nutrients for use in patients in the peri-operative period are urgently required.

\section{REFERENCES}

Adjei, A. A., Takamine, F. T., Yokoyama, H., Shiokawak, K., Matsumoto, Y., Asato, L., Shimjo, S., Imamura, T. \& Yamamoto, S. (1993). The effects of oral RNA and intra-peritoneal nucleoside-nucleotide administration on methicillin-resistant Staphylococcus aureus infection in mice. Journal of Parenteral and Enteral Nutrition $17,148-152$. 
Alexander, J. W., Saito, H., Ogle, C. K. \& Trocki, O. (1986). The importance of lipid type in the diet after burn injury. Annals of Surgery 204, 1-8.

Almallah, Y. Z., O'Hanrahan, T. J., Richardson, S., Mowat, N. A. G., Brunt, P. W., Sinclair, T. S., Heys, S. D. \& Eremin, O. (1996). Inhibition of natural cytotoxicity with eicosapentaenoic and docosahexaenoic acids: possible mechanism(s). British Journal of Surgery 83, 685 Abstr.

Barbul, A., Lazarou, S. A., Efron, D. T., Wasserbrug, H. L. \& Efron, G. (1990). Arginine enhances wound healing and lymphocyte immune responses in humans. Surgery 108, 331-337.

Barbul, A., Rettura, G. \& Levenson, S. M. (1977). Arginine: a thymotropic and wound healing promoting agent. Surgical Forum 28, 101-103.

Barbul, A., Sisto, D. A., Wasserbrug, H. L. \& Efron, G. (1981). Arginine stimulates lymphocyte immune response in healthy human beings. Surgery 90, 244-251.

Barton, R. G., Wells, C. L., Carlson, A., Singh, R., Sullivan, J. J. \& Cerra, F. B. (1991). Dietary omega-3 fatty acids decrease mortality and Kupfer cell prostaglandin $\mathrm{E}_{2}$ production in a rat model of chronic sepsis. Journal of Trauma 31, 768-773.

Bastow, M. D., Rawlings, J. \& Allison, S. P. (1983). Benefits of supplementary tube feeding after fractured neck of femur: a randomised controlled trial. British Medical Journal 287, 1589-1592.

Bergstom, J., Furst, P., Noree, L.-O. \& Vinnars, E. (1974). Intracellular free amino acid concentration in human muscle tissue. Journal of Applied Physiology 36, 693-696.

Bower, R. H., Cerra, F. B., Bershadsky, B., Licari, J. J., Hoyt, D. B., Jensen, G. L., Van Buren, C. T., Rothkopf, M. M., Daly, J. M. \& Adelsberg, B. R. (1995). Early enteral administration of a formula (Impact) supplemented with arginine, nucleotides, and fish oil in intensive care unit patients: results of a multicenter, prospective, randomized, clinical trial. Critical Care Medicine 23, 436-449.

Brittenden, J., Heys, S. D., Ross, J., Park, K. G. M. \& Eremin, O. (1994a). Nutritional pharmacology: effects of L-arginine on host defences, response to trauma and tumour growth. Clinical Science 86, 123-132.

Brittenden, J., Heys, S. D., Ross, J., Park, K. G. M. \& Eremin, O. (1994b). Natural cytotoxicity in breast patients receiving neoadjuvant chemotherapy: effects of L-arginine supplementation. European Journal of Surgical Oncology 20, 467-472.

Carr, C. S., Ling, K. D. E., Boulos, P. \& Singer, M. (1996). Randomised trial of safety and efficacy of immediate postoperative enteral feeding in patients undergoing gastrointestinal resection. British Medical Journal 312, 869-871.

Cerra, F. B., Lehman, S., Konstantinides, N., Konstantinides, F., Shronts, E. P. \& Holman, R. (1990). Effect of enteral nutrition on in vitro tests of immune function in ICU patients: a preliminary report. Nutrition 6, 84-87.

Clouva-Molyvdas, P., Peak, M. D. \& Alexander, J. W. (1992). Short-term dietary lipid manipulation does not affect survival in two models of murine sepsis. Journal of Parenteral and Enteral Nutrition 16, 343-347.

Daly, J. M., Lieberman, M. D., Goldfine, J., Shou, J., Weintraub, F., Rosato, E. F. \& Lavin, P. (1992). Enteral nutrition with supplemental arginine, RNA, and omega-3 fatty acids in patients after operation: Immunologic, metabolic, and clinical outcome. Surgery 112, 56-67.

Daly, J. M., Reynolds, J., Thom, A., Kinsley, L., Dietrick-Gallagher, M., Shou, J. \& Ruggieri, B. (1988). Immune and metabolic effects of arginine in the surgical patient. Annals of Surgery 208, 513-523.

Daly, J. M., Weintraub, E. N., Shou, J., Rosato, E. F. \& Lucia, M. (1995). Enteral nutrition during multimodality therapy in upper gastrointestinal cancer patients. Annals of Surgery 221, 327-338.

Delmi, M., Rapin, C.-H., Bengoa, J.-M., Delmas, P. D., Vasey, H. \& Bonjour, J.-P. (1990). Dietary supplementation in elderly patients with fractured neck of the femur. Lancet 335, 1013-1016.

Detsky, A. S., Baker, J. P., O'Rourke, K., Johnston, N., Whitewell, J., Mendelson, R. A. \& Jeejeebhoy, K. N. (1987). Predicting nutrition-associated complications for patients undergoing gastrointestinal surgery. Journal of Parenteral and Enteral Nutrition 11, 440-446.

Donner, M., Vaillier, O. \& Lacour, F. (1977). Changes in lymphocyte subpopulations in mice receiving a single injection of poly(A). poly(U). Annals of Immunology of the Institute Pasteur 128, 1039-1052.

Dy, M., Arnould, A. \& Schneider, E. (1991). Poly(A)-Poly(U) induces circulating colony-stimulating activity resulting from interactions between endogenous interleukin 6 and serum components. Experimental Haematology 19, 261-266.

Elsair, J., Poey, J. \& Isaad, J. (1978). Effect of arginine chlorhydrate on nitrogen balance during the three days following surgery in man. Biomedicine 29, 312-317.

Fan, S.-T., Lo, C.-M., Lai, E. C. S., Chu, K.-M., Liu, C.-L. \& Wong, J. (1994). Perioperative nutritional support in patients undergoing hepatectomy for hepatocellular carcinoma. New England Journal of Medicine 331, $1547-1552$.

Frankel, A. M. \& Horowitz, G. D. (1989). Nasoduodenal tubes in short-stay cholecystectomy. Surgery, Gynecology and Obstetrics 168, 433-436.

Gianotti, L., Braga, M., Vignali, A., Cestari, A. \& Di Carlo, V. (1996). Clinical outcome of patients undergoing major abdominal operation and fed enterally shortly after surgery. British Journal of Surgery 83,853 Abstr.

Guedon, C., Schmitz, J., Lerebours, E., Metayer, J., Audren, E., Hermet, J. \& Colin, R. (1986). Decreased brush border hydrolase activities without gross morphologic changes in human intestinal mucosa after prolonged total parenteral nutrition of adults. Gastroenterology 90, 373-378. 
Hammarqvist, F., Wernerman, J., Ali, R., von der Decken, A. \& Vinnars, E. (1989). Addition of glutamine to total parenteral nutrition after elective abdominal surgery spares free glutamine in muscle, counteracts the fall in muscle protein synthesis, and improves nitrogen balance. Annals of Surgery 209, 455-461.

Heatley, R. V., Williams, R. H. P. \& Lewis, M. H. (1979). Preoperative intravenous feeding: a controlled trial. Postgraduate Medical Journal 55, 541-545.

Heys, S. D., Gough, D. B., Khan, A. L. \& Eremin, O. (1996). Nutritional pharmacology and malignant disease: a therapeutic modality in patients with cancer. British Journal of Surgery 83, 608-619.

Hill, G. L. (editor) (1992). In Disorders of Nutrition and Metabolism in Clinical Surgery. Edinburgh: Churchill Livingstone.

Holter, A. R. \& Fischer, J. E. (1977). The effects of perioperative hyperalimentation on complications in patients with carcinoma and weight loss. Journal of Surgical Research 23, 31-34.

Hoover, H. C., Ryan, J. A., Anderson, E. J. \& Fischer, J. E. (1980). Nutritional benefits of immediate postoperative jejunal feeding of an elemental diet. American Journal of Surgery 139, 153-159.

Kemen, M., Senkal, M., Homann, H.-H., Mumme, A., Dauphin, A.-K., Baier, J., Windeler, J., Neumann, H. \& Zumtobel, V. (1995). Early post-operative enteral nutrition with arginine- $\omega$-3 fatty acids and ribonucleic acidsupplemented diet versus placebo in cancer patients: An immunologic evaluation of Impact. Critical Care Medicine 23, 652-659.

Khan, A. L., Heys, S. D. \& Eremin, O. (1995a). Synthetic polyribonucleotides: current role and potential use in oncological practice. European Journal of Surgical Oncology 21, 224-227.

Khan, A. L., Richardson, S., Drew, J., Larsen, F., Campbell, M., Heys, S. D., Ah-See, A. K. \& Eremin, O. $(1995 b)$. Polyadenylic-polyuridylic acid (PAPU) enhances natural cell-mediated cytotoxicity in patients with breast cancer undergoing mastectomy. Surgery 115, 531-538.

Kinsella, J. E. \& Lokesh, B. (1990). Dietary lipids, eicosanoids and the immune system. Critical Care Medicine 18, S94-S113.

Kirk, S. J. \& Barbul, A. (1990). Role of arginine in sepsis, trauma and immunity. Journal of Parenteral and Enteral Nutrition 14, 226S-229S.

Li, M., Specian, R. D., Berg, R. D. \& Deitch, E. A. (1989). Effects of protein malnutrition on the intestinal muscosal barrier to the translocation of indigenous flora in mice. Journal of Parenteral and Enteral Nutrition $13,572-578$.

Mainous, M., Xu, D. Z., Lu, Q., Berg, R. D. \& Deitch, E. A. (1991). Oral-TPN-induced bacterial translocation and impaired immune defences are reversed by refeeding. Surgery 110, 277-283.

Mascioli, E. A., Iwassa, Y., Trimbo, S., Leader, L., Bistrian, B. R. \& Blackburn, G. L. (1989). Endotoxin challenge after menhaden oil; effects on survival of guinea pigs. American Journal of Clinical Nutrition 49, 277-282.

Meguid, M. M., Campos, A. A. \& Hammond, W. G. (1990). Nutritional support in surgical practice: part 1. American Journal of Surgery 159, 345-358.

Meijerink, W. J. H. J., von Meyenfeldt, M. F., Rouflart, M. M. J. \& Soeters, P. B. (1992). Efficacy of postoperative nutritional support. Lancet 340, 187-188.

Meydani, S. N., Endres, S., Woods, M. M., Goldin, B. R., Soo, C., Morrill-Labrode, A., Dinarello, C. A. \& Garbach, S. L. (1991). Oral ( $n-3)$ fatty acid supplementation suppresses cytokine production and lymphocyte proliferation: comparison between young and older women. Journal of Nutrition 121, 547-555.

Moghissi, K., Hornshaw, J., Teasdale, P. R. \& Dawes, E. (1977). Parenteral nutrition in carcinoma of the oesophagus treated by surgery: nitrogen balance and clinical studies. British Journal of Surgery 64, $125-128$.

Moore, F. A., Feliciano, D. V., Andrassy, R. J., McArdle, A. H., Booth, F. V. M., Morgenstein-Wagner, T. B., Kellum, J. M., Welling, R. E \& Moore, E. E. (1992). Early enteral feeding, compared with parenteral, reduced postoperative septic complications. Surgery 216, 172-183.

Moore, F. A., Moore, E. E., Kudsk, K. A., Brown, R. O., Bower, R. H., Koruda, M. J., Baker, C. C. \& Barbul, A. (1994). Clinical benefits of an immune-enhancing diet for early postinjury enteral feeding. Journal of Trauma $37,607-615$.

Morris, C. K. \& Johnson, A. G. (1978). Regulation of the immune system by synthetic polyribonucleotides VII. Suppression induced by pre-treatment with poly A:U. Cellular Immunology 39, 345-354.

Mullen, J. L., Buzby, M. D., Mathews, D. C., Smale, B. F. \& Rosato, E. F. (1980). Reduction of operative morbidity and mortality by combined pre-operative and post-operative nutritional support. Annals of Surgery 192, 604-613.

Muller, J. M., Dienst, C., Brenner, U. \& Pichlmairer, H. (1982). Preoperative parenteral feeding in patients with gastrointestinal carcinoma. Lancet i, 68-71.

O'Riordain, M. G., Fearon, K. C. H., Ross, J. A., Rogers, P., Falconer, J. S., Bartolo, D. C. C., Garden, O. J. \& Carter, D. C. (1994). Glutamine-supplemented total parenteral nutrition enhances T-lymphocyte response in surgical patients undergoing colorectal resection. Annals of Surgery 220, 212-221.

Park, K. G. M., Hayes, P. D., Garlick, P. J., Sewell, H. F. \& Eremin, O. (1991). Stimulation of lymphocyte natural cytotoxicity by L-arginine. Lancet 337, 645-646.

Purasiri, P., Ashby, J., Heys, S. D. \& Eremin, O. (1994a). Effect of essential fatty acids on circulating T cell subsets in patients with colorectal cancer. Cancer Immunology and Immunotherapeutics 39, 217-222. 
Purasiri, P., Ashby, J., Heys, S. D. \& Eremin, O. (1995). Effect of essential fatty acids on natural cytotoxicity in patients with colorectal cancer. European Journal of Surgical Oncology 21, 254-260.

Purasiri, P., Murray, A., Richardson, S., Heys, S. D., Horrobin, D. \& Eremin, O. (1994b). Modulation of cytokine production in vive by dietary essential fatty acids in patients with colorectal cancer. Clinical Science 87, 711-717.

Roth, E., Furnovics, J. \& Muhlbacher, F. (1982). Metabolic disorders in severe abdominal sepsis: glutamine deficiency in skeletal muscle. Clinical Nutrition 1, 25-41.

Ryan, J. A., Page, C. P. \& Babcock, L. (1981). Early postoperative jejunal feeding of elemental diet in gastrointestinal surgery. American Surgeon 47, 393-403.

Sagar, P., Harland, P. \& Shields, R. (1979). Early postoperative feeding with elemental diet. British Medical Journal 1, 293-295.

Schroeder, D., Gillanders, L., Mahr, K. \& Hill, G. L. (1991). Effects of immediate postoperative enteral nutrition on body composition, muscle function and wound healing. Journal of Parenteral and Enteral Nutrition 15, 376-383.

Sedman, P. C., Macfie, J., Sagar, P., Mitchell, C. J., May, J., Mancey-Jones, B. \& Johnstone, D. (1994). The prevalence of gut translocation in humans. Gastroenterology 107, 643-649.

Shukla, H. S., Rao, R. R., Banu, N., Gupta, R. M. \& Yadav, R. C. (1984). Enteral hyperalimentation in malnourished surgical patients. Indian Joumal of Medical Research 80, 339-346.

Smith, R. C., Hartemink, R. J., Hollinshead, J. W. \& Gillett, D. J. (1985). Fine bore jejunostomy feeding following major abdominal surgery: a controlled randomized clinical trial. British Journal of Surgery 72, 458461.

Studley, H. O. (1936). Percentage of weight loss. A basic indicator of surgical risk in patients with chronic peptic ulcer. Journal of the American Medical Association 106, 458-460.

van der Hulst, R. R. W., van Kreel, B. K., von Meyenfeldt, M. F., Brummer, R. J., Arends, J. W., Deutz, N. E. \& Soeters, P. B. (1993). Glutamine and the preservation of gut integrity. Lancet 341, 1363-1365.

Veterans Affairs Total Parenteral Nutrition Co-operative Study Group (1991). Perioperative total parenteral nutrition in surgical patients. New England Journal of Medicine 325, 525-532.

von Meyenfeldt, M. F., Meijerink, W. J. H. J., Rouflart, M. M. J., Buil-Maassen, M. T. H. J. \& Soeters, P. B. (1992). Perioperative nutritional support: a randomised clinical trial. Clinical Nutrition 11, 180-186.

Windsor, A. C. J., Li, A., Guthrie, A., Barnes, E., Somers, S. S., Welsh, F., Guillou, P. J. \& Reynolds, J. V. (1996). Feeding the gut in acute pancreatitis: a randomised clinical trial of enteral versus parenteral nutrition. British Journal of Surgery 83, 689 Abstr.

Youn, J. K., Kim, B. S., Min, J. S., Lee, K. S., Choi, H. J., Lee, Y. B., Lee, D. W., Park, I. S., Roh, J. K., Chung, J. B., Koh, E. H., Park, Y. J., Kim, H. I. \& Lee, K. B. (1987). Adjuvant treatment of operable stomach cancer with polyadenylic-polyuridylic acid in addition to chemotherapeutic agents. Differential effect on natural killer cell activity and antibody-dependent cellular cytotoxicity. International Joumal of Immunopharmacology 9, 313-324.

Ziegler, T. R., Young, L. S., Benfell, K., Scheltinga, M., Hortos, K., Bye, R., Morrow, F. D., Jacobs, D. O., Smith, R. J., Antin, J. H. \& Wilmore, D. W. (1992). Clinical and metabolic efficacy of glutaminesupplemented parenteral nutrition after bone marrow transplantation. Annals of Internal Medicine 116, 821828 . 